\title{
Apoptotic index for prediction of postmolar gestational trophoblastic neoplasia
}

\author{
Antonio Braga, MD; Izildinha Maestá, MD; Renan Rocha Soares, MD; Kevin M. Elias, MD; \\ Maria Aparecida Custódio Domingues, MD; Luis Fernando Barbisan, PhD; Ross S. Berkowitz, MD
}

BACKGROUND: Although 85\% of patients with a complete hydatidiform mole achieve spontaneous remission after a few months, 15\% of them will experience gestational trophoblastic neoplasia, which requires chemotherapy. To date, there is no biomarker to predict post-molar gestational trophoblastic neoplasia before the initiation of human chorionic gonadotropin surveillance.

OBJECTIVE: The purpose of this study was to assess the relationship between the expression of apoptosis markers in the molar villous trophoblasts and the subsequent development of gestational trophoblastic neoplasia after the evacuation of a complete hydatidiform mole.

STUDY DESIGN: This was a retrospective cohort study of patients with complete hydatidiform mole who were diagnosed, treated, and followed at the Center of Trophoblastic Diseases (Botucatu/São Paulo State and Rio de Janeiro/Rio de Janeiro State, Brazil) from 1995-2014. Patients were divided temporally into derivation (1995-2004) and validation (2005-2014) cohorts. Immunohistochemistry was used to examine tissue expression of the apoptosis inhibitor survivin or the pro-apoptotic enzyme caspase-3. Survivin stains for cytoplasmic and nuclear expression were evaluated independently. Caspase-3 expression was measured as an apoptotic index of positive staining cells over negative staining cells multiplied by 100 . Receiver operating characteristic curves were then constructed, and the area under the curve was calculated to test the performance characteristics of the staining to predict the subsequent development of gestational trophoblastic neoplasia.
RESULTS: The final study population comprised 780 patients, with 390 patients in each temporal cohort: 590 patients entered spontaneous remission, and 190 patients experienced post-molar gestational trophoblastic neoplasia. Neither nuclear nor cytoplasmic survivin expression performed well as a predictor of subsequent gestational trophoblastic neoplasia. The caspase-3 apoptotic index was a strong risk factor for subsequent gestational trophoblastic neoplasia development. When the apoptotic index was $<4 \%$, the risk of gestational trophoblastic neoplasia had an odds ratio of 35.55 (95\% confidence interval, 14.02-90.14; $P<.0001)$ in the derivation cohort and an odds ratio of 25.71 (95\% confidence interval, 10.13-65.29; $P<.0001$ ) in the validation cohort. However, in both cohorts, the positive predictive value for gestational trophoblastic neoplasia of an apoptotic index $<4.0 \%$ was modest (49\% in the derivation cohort and $41 \%$ in the validation cohort); the negative predictive value for gestational trophoblastic neoplasia of an apoptotic index $\geq 4.0 \%$ was high ( $97 \%$ in both cohorts).

CONCLUSION: The subsequent development of gestational trophoblastic neoplasia after evacuation of complete hydatidiform mole is tied closely to the apoptotic index, which may be a useful biomarker for future prospective studies.

Key words: apoptotic index, Brazil, complete hydatidiform mole, gestational trophoblastic neoplasia, receiver operating characteristic, survivin omplete hydatidiform mole (CHM) is a reproductive anomaly that occurs because of a lack of maternal chromosome expression and is characterized by diffuse hydropic villi, marked trophoblastic hyperplasia, and the absence of fetal vessels. ${ }^{1,2}$ Although $85 \%$ of patients with a CHM achieve spontaneous remission after a few months, $15 \%$ will experience gestational trophoblastic neoplasia (GTN), which requires chemotherapy. ${ }^{3}$ Detection of persistence after evacuation of a CHM relies on strict

Cite this article as: Braga A, Maestá I, Soares RR, et al. Apoptotic index for prediction of postmolar gestational trophoblastic neoplasia. Am J Obstet Gynecol 2016;215: 336.e1-12.

0002-9378/\$36.00

(c) 2016 Elsevier Inc. All rights reserved.

http://dx.doi.org/10.1016/j.ajog.2016.04.010 postmolar follow-up evaluation with human chorionic gonadotropin (hCG) surveillance, which is the only marker capable of detecting GTN at an early stage. ${ }^{4}$ Efforts to predict postmolar GTN before the initiation of hCG surveillance, such as using the histologic condition of the trophoblastic tumor, ${ }^{5}$ the ploidy assessment of DNA by cytometry, ${ }^{6}$ cell proliferation markers, ${ }^{7}$ and oncogene expression $^{8}$ have been unsuccessful. However, a marker that could prognosticate postmolar GTN would have high clinical utility. Patients with CHM at a high risk of experiencing postmolar GTN could be treated with prophylactic chemotherapy, especially in settings in which it is difficult to maintain a rigorous follow-up regimen. ${ }^{9}$ Furthermore, the identification of the patients who are at very low risk of persistence could allow shortened surveillance (especially after hCG reaches normal levels) and the reduction of patient anxiety, work absence, and healthcare costs. ${ }^{10,11}$

Preliminary reports have suggested a relationship between programmed cell death, or apoptosis, and postmolar GTN. ${ }^{12-16}$ Depending on the stimulus, trophoblast apoptosis could be initiated by the intrinsic (mitochondria-dependent) or the extrinsic pathway, mediated by death receptors on the surface of the cell membrane. The intrinsic and extrinsic pathways for trophoblast apoptosis are not mutually exclusive, and both could be activated. ${ }^{17}$ These pathways culminate in the action of aspartate-specific proteases called caspases (cysteine - aspartic acid - proteases), which are responsible for the mediation of cell death by proteolysis at aspartic acid residues. There are also 
mechanisms for the control of programmed cell death, such as the action of the inhibitor of apoptosis family of proteins, particularly survivin. Survivin is a $16.5 \mathrm{kDA}$ molecule that is expressed during the G2/M phase and is located in the microtubules of mitotic spindles, where it regulates apoptosis by ensuring proper chromosome segregation and cytokinesis. ${ }^{18,19}$ The aim of this study was to evaluate the potential for markers of apoptosis to serve as predictive biomarkers for the risk of GTN after evacuation of a CHM.

\section{Materials and Methods} Design

This was a retrospective cohort study of patients who had been diagnosed with CHM after uterine evacuation and observed and treated at the Trophoblastic Disease Center of São Paulo State University, Botucatu Medical School, and the Rio de Janeiro Trophoblastic Disease Center (33rd Maternity Ward at Santa Casa da Misericórdia) between 1995 and 2014. The research was approved by the Institutional Review Board of the Botucatu Medical School at São Paulo State University (protocol number 497/2007). All the patients previously had given informed consent for participation. Patients were divided into a derivation cohort (comprised of women treated for CHM between 1995 and 2004) and a validation cohort (comprised of women treated for CHM between 2005 and 2014).

\section{Patients}

The patients who participated in this study had been diagnosed with CHM, which was confirmed by histopathologic evaluation, and had their molar tissue embedded in paraffin blocks and stored at the Department of Pathology at Botucatu Clinical Hospital at São Paulo State University and the 33rd Maternity Ward of Santa Casa da Misericórdia do Rio de Janeiro. The patients also attended complete postmolar follow-up evaluation at the reference centers for at least 1 year. Patients were excluded if there was not enough histologic material stored for the immunohistochemical study of the molar tissue or there was inadequate material for this study.

Spontaneous remission was defined as 3 consecutive weekly hCG measurements of $<5 \mathrm{IU} / \mathrm{L}$. Progression from CHM to GTN was diagnosed by Fédération Internationale de Gynécologie et d'Obstétrique (FIGO) $\operatorname{criteria}^{20}$ : rising (>10\%) hCG levels for 3 consecutive weeks or plateaued for 4 weeks. Patients with a histologic diagnosis of choriocarcinoma or metastases that was detected during postmolar follow-up evaluation, particularly in the lungs and pelvis, were also classified as GTN cases. Before chemotherapy was started, the patients were evaluated for metastatic disease by gynecologic examination, Doppler ultrasonography of the pelvis, and chest radiograph to check for any pulmonary metastases. GTN was staged according to the FIGO 2000 criteria: I, disease confined to the uterus; II, disease extends to the outside of the uterus but is limited to the genital structures; III, disease extends to the lungs, with or without genital tract involvement; and IV, all other metastatic sites. ${ }^{20}$

Prognostic scoring for resistance to chemotherapy followed the FIGO/World Health Organization Prognostic Scoring System. All patients in the current study with postmolar GTN were classified as low risk according to their FIGO 2000 risk factor score ${ }^{20}$ and received singleagent chemotherapy (methotrexate or actinomycin-D). Resistance to primary chemotherapy treatment was defined by rising or plateaued hCG levels for at least 3 consecutive weeks. Patients with resistance to single agent chemotherapy received combination chemotherapy (etoposide, methotrexate, actinomycin D/cyclophosphamide and vincristine or etoposide and cisplatin/etoposide, methotrexate, actinomycin D). ${ }^{21}$ After chemotherapy, all the patients underwent follow-up evaluation for at least 1 year with monthly hCG surveillance after the first normal hCG value was obtained.

\section{Pathologic condition}

The diagnosis of CHM was confirmed by a histologic review of each case by 1 pathologist at each reference center who was not informed of the clinical progression of the disease, using the criteria described by Szulman and Surti ${ }^{22}$ : diffuse swelling of chorionic villi with edema, central cistern formation, absence of embryo, and abnormal trophoblast hyperplasia. From 2010 onwards, p5 $7^{\text {kip2 }}$ immunohistochemistry was used routinely in all cases to distinguish complete from partial mole. For this study, all cases before 2010 were also reviewed, and any case in which there was a question of complete or partial mole was stained for $\mathrm{p} 57^{\mathrm{kip} 2}$.

\section{Immunohistochemical study}

Histologic sections were made from each paraffin block. Slides were deparaffinized with the use of Xylenes and sequential washes with graded ethanols. Slides were then stained according to an avidin-biotin-peroxidase technique. The following primary antibodies were used in each case: rabbit polyclonal cleaved caspase-3 antibody (Asp175; 1:200 dilution; Cell Signaling Technology, Danvers, MA) and mouse monoclonal survivin antibody (clone 5E8; 1:100 dilution; Neomarkers, Fremont, CA). The histologic sections with the primary antibodies were incubated overnight at $4^{\circ} \mathrm{C}$.

The sections were interpreted simultaneously by 2 separate observers who were blinded to the clinical outcome using an optical microscope (Olympus, model BX40; Olympus Corporation, Tokyo, Japan) with $\times 100$ and $\times 400$ magnification. The entire length of each section was observed to select the fields with the most villous trophoblast cells. Histologic sections of tonsil tissue for caspase-3 and gastric cancer for the expression of survivin were used as positive controls. Sections that had been incubated without primary antibodies served as negative controls. Only brown staining in the villous trophoblast cells was considered positive. To measure possible interobserver variation in the interpretation of the immunohistochemical sections, a selection of 30 cases were reviewed independently by 2 pathologists and scored for apoptotic index and nuclear and cytoplasmic survivin staining. The Pearson correlation 
coefficient between the 2 sets of scores was 0.999 for the apoptotic index and 0.992 for both the nuclear and cytoplasmic survivin staining.

\section{Evaluation of immunoexpression of survivin}

Nuclear and cytoplasmic stainings for survivin were scored separately. Intensity and extent of survivin immunoexpression were categorized by a semiquantitative method: negative, weak, moderate, or strong intensity of staining were scored as 0 (negative), 1 $(+), 2(++)$, and $3(+++)$. The extent of staining was either no staining, up to one-third of cells stained, one to twothirds stained, and more than twothirds stained, which were scored as 0 (negative), $1(+), 2(++)$, and 3 $(+++)$, respectively. The final survivin immunoexpression score resulted from summing the intensity and extent scores (Supplemental Figure 1).

\section{Evaluation of apoptotic index}

Cells were counted with the use of an eyepiece reticule $(\times 400$ magnification, which corresponded to $0.25 \mathrm{~mm}^{2}$; Olympus Eyepiece Micrometer; Olympus Corporation, Tokyo, Japan). Cells at the edges of the fields or with unclear nuclei were not counted. On average, $755 \pm 80$ trophoblastic cells were counted in the spontaneous remission group and $721 \pm 87$ in the GTN group $(P=.12)$. The apoptotic index was calculated with a previously described formula, the ratio between the number of caspase-3-positive cells and the total number of cells analyzed multiplied by 100 (Supplemental Figure 2). ${ }^{13,23}$

\section{Statistical analysis}

Parametric statistics were performed with the Student $t$ test, and nonparametric tests were performed with the Mann-Whitney $U$ test. Proportions among groups were compared with the use of a Fisher's exact test, and linear trends were analyzed with the MantelHaenszel chi-square test. Confidence intervals for proportions were calculated according to the modified Wald method. After the patient slides had been scored

\section{FIGURE 1}

\section{Flow diagram}

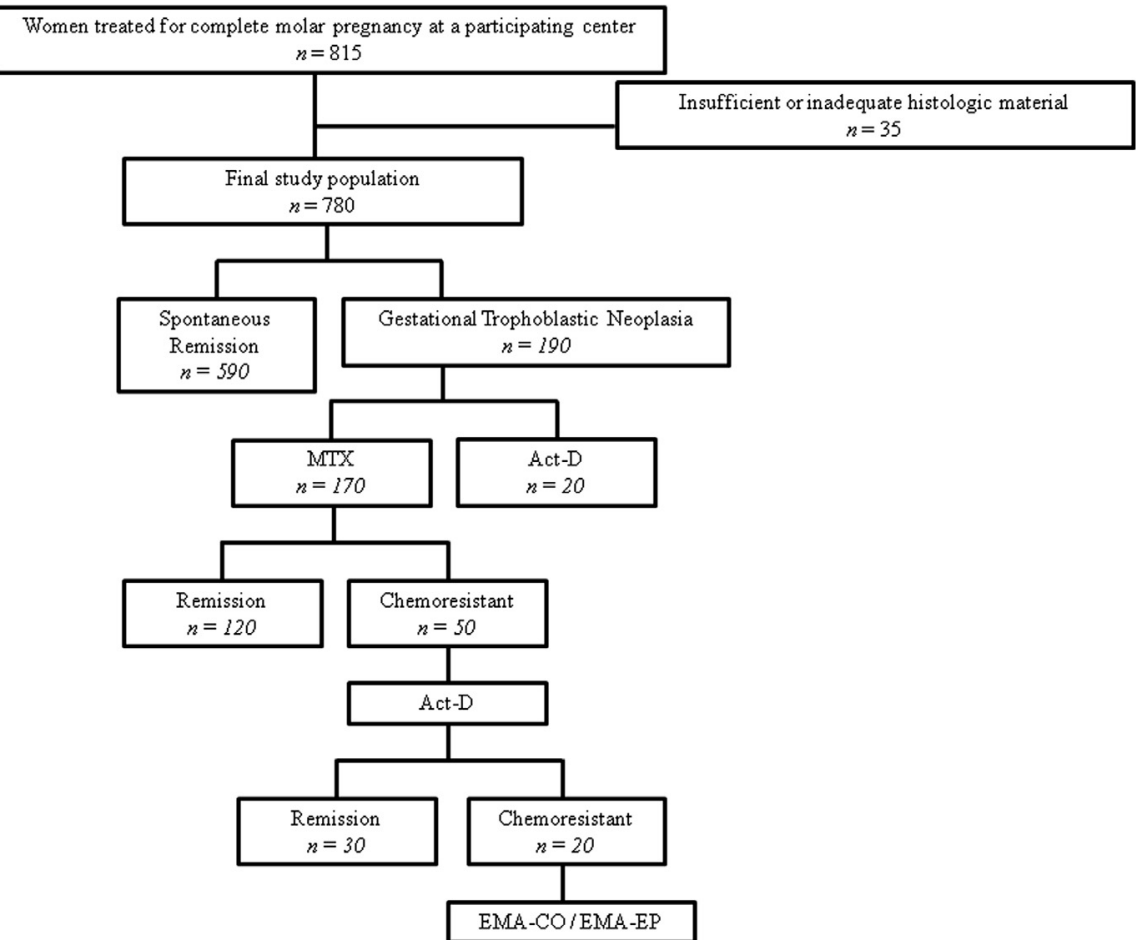

Flow diagram shows the selection of the study population and subsequent clinical outcomes.

Act-D, actinomycin-D; EMA-CO, etoposide, methotrexate, actinomycin D/cyclophosphamide and vincristine; $E M A-E P$, etoposide and cisplatin/etoposide, methotrexate, actinomycin D; MTX, methotrexate.

Braga et al. Apoptotic index for prediction of postmolar GTN. Am J Obstet Gynecol 2016.

for the apoptotic index, nuclear survivin expression, and cytoplasmic survivin expression, the results were grouped into strata. The risk of GTN was calculated for each $1 \%$ increase in the apoptotic index or each 1-point increase in the survivin immunohistochemistry score. Receiver operating characteristic (ROC) curves were then constructed, and the area under the curve (AUC) was calculated to test the performance characteristics of these classifications with the use of OpenEpi software, version 3.03a. ${ }^{24}$ Beta coefficients were calculated with multiple logistic regression analysis with SPSS software (version 21.0; SPSS Inc, Chicago, IL). For each test, a probability value of $<.05$ was considered statistically significant.

\section{Results}

During the study period, 815 patients were treated at the involved centers for CHM (Figure 1). On review, 35 patients were excluded from the study because there was not enough histologic material stored for the immunohistochemical examination or because it was inadequate for this study, which left a final study population of 780 patients. In postmolar follow-up evaluation, 590 patients achieved spontaneous remission, and 190 experienced postmolar GTN. None of the 20 patients who received actinomycin-D as the primary treatment had chemotherapy resistance. Of the 170 patients who received methotrexate, 50 patients $(29.4 \%)$ experienced resistance and subsequently were treated with actinomycin-D. Twenty of these 50 patients experienced chemoresistance to actinomycin-D and had to be given combination chemotherapy. All patients eventually entered full remission. We considered whether the apoptotic index or survivin expression would be a surrogate biomarker for outcome for patients once the diagnosis 


\section{TABLE 1}

\section{Clinical characteristics of the study cohorts}

\begin{tabular}{|c|c|c|c|}
\hline Characteristic & Spontaneous remission $^{a}$ & Gestational trophoblastic neoplasia $^{\mathrm{b}}$ & $P$ value \\
\hline \multicolumn{4}{|l|}{ Derivation cohort, 1995-2004 } \\
\hline Age, $y^{c}$ & $22 \pm 5.8$ & $26 \pm 6.3$ & $<.0001^{\mathrm{d}}$ \\
\hline Gravidity, $\mathrm{n}^{\mathrm{c}}$ & $0 \pm 1.0$ & $0 \pm 0.8$ & $1.0^{\mathrm{e}}$ \\
\hline Parity, $\mathrm{n}^{\mathrm{C}}$ & $0 \pm 0.9$ & $0 \pm 0.9$ & $1.0^{\mathrm{e}}$ \\
\hline Gestational age at diagnosis, $\mathrm{wk}^{\mathrm{C}}$ & $12 \pm 4.2$ & $13 \pm 2.9$ & $.03^{\mathrm{d}}$ \\
\hline Uterine size greater than dates, $\mathrm{n}(\%)$ & $158(55)$ & $77(74.7)$ & .0006 \\
\hline Presence of theca-lutein cysts, $\mathrm{n}(\%)$ & $66(22.9)$ & $70(67.9)$ & $<.0001^{\dagger}$ \\
\hline Initial human chorionic gonadotropin level (IU/L) & $158978 \pm 255998$ & $613229 \pm 587122$ & $.001^{\mathrm{e}}$ \\
\hline Time to remission, $w^{c}$ & $10 \pm 2.9$ & $17 \pm 4.7$ & $<.0001^{d}$ \\
\hline \multicolumn{4}{|l|}{ Validation cohort, 2005-2014 } \\
\hline Age, $\mathrm{y}^{\mathrm{c}}$ & $20 \pm 4.9$ & $25 \pm 6.9$ & $<.0001^{d}$ \\
\hline Gravidity, $\mathrm{n}^{\mathrm{c}}$ & $0 \pm 1.0$ & $0 \pm 0.9$ & $1.0^{\mathrm{e}}$ \\
\hline Parity, $\mathrm{n}^{\mathrm{C}}$ & $0 \pm 0.9$ & $0 \pm 1.0$ & $1.0^{\mathrm{e}}$ \\
\hline Gestational age at diagnosis, $\mathrm{wk}^{\mathrm{C}}$ & $13 \pm 2.9$ & $13 \pm 3.4$ & $1.0^{\mathrm{d}}$ \\
\hline Uterine size greater than dates, $\mathrm{n}(\%)$ & $152(50.1)$ & $63(72.4)$ & $.0003^{f}$ \\
\hline Presence of theca-lutein cysts, $n(\%)$ & $74(24.4)$ & $40(45.9)$ & $.0002^{f}$ \\
\hline Initial human chorionic gonadotropin level (IU/L) & $146978 \pm 245891$ & $501133 \pm 632677$ & $<0001^{\mathrm{e}}$ \\
\hline Time to remission, $w^{C}$ & $10 \pm 3.1$ & $17 \pm 4.9$ & $<.0001^{\mathrm{d}}$ \\
\hline
\end{tabular}

of GTN was made. Neither biomarker appeared related to the time to initiate chemotherapy, presence of metastases, chemoresistance, or the need for multiagent chemotherapy (Supplemental Table 1).

The total study population was then divided into 2 temporal cohorts to derive and then validate prognostic scores for the apoptotic index and survivin expression. Patients who were treated at the reference center from 1995-2004 were used as the derivation cohort, and patients who were treated at the reference center from 2005-2014 were used as the validation cohort. Clinical characteristics of the 2 cohorts are presented in Table 1. Differences between the patients who achieved spontaneous remission vs those who experienced GTN were similar in both cohorts. Consistent with previous reports, patients who went on to experience GTN were significantly older, had larger uteri on presentation, were more likely to have theca lutein cysts, had higher initial hCG levels, and required a longer time to reach remission than patients who had spontaneous remission.

To test the predictive value of apoptosis markers, we began by looking at cytoplasmic and nuclear survivin expression (Supplemental Table 2). In the derivation cohort, immunohistochemistry scores for cytoplasmic survivin tended to be lower in women who had GTN compared with those who achieved spontaneous remission $(P$ trend $=.02)$. However, the apparent relationship between cytoplasmic survivin expression and GTN was not reproduced in the validation cohort $(P$ trend $=.74)$. In contrast, although the trend for lower nuclear survivin scores among women who had GTN did not quite reach statistical significance in the derivation cohort $(P$ trend $=.08)$, there appeared to be a stronger association in the validation cohort $(P$ trend $=.005)$. However, Figure 2 shows that, when
ROC curves were constructed for cytoplasmic and nuclear survivin expression for both cohorts, neither biomarker had strong performance characteristics; both cytoplasmic and nuclear survivin expression were only slightly better than chance alone.

Next, we looked at the relationship between the apoptotic index and the subsequent development of GTN (Supplemental Table 3). Apoptotic indices tended to be low in women who experienced GTN and high in women who achieved spontaneous remission $(P$ trend $<.0001$ in both cohorts). In both the derivation (AUC $=0.78$; 95\% confidence interval $[\mathrm{CI}], 0.73-0.83$ ) and the validation cohorts $(\mathrm{AUC}=0.74 ; 95 \%$ CI, $0.68-0.80)$, the apoptotic index performed relatively well in the prediction of the subsequent development of GTN (Figure 3). Based on the ROC curves, the optimum cut-off for the prediction of GTN appeared to be an apoptotic index of $4.0 \%$ (Table 2). In the 


\section{FIGURE 2}

\section{Performance characteristics of survivin expression as predictor of GTN following complete mole}

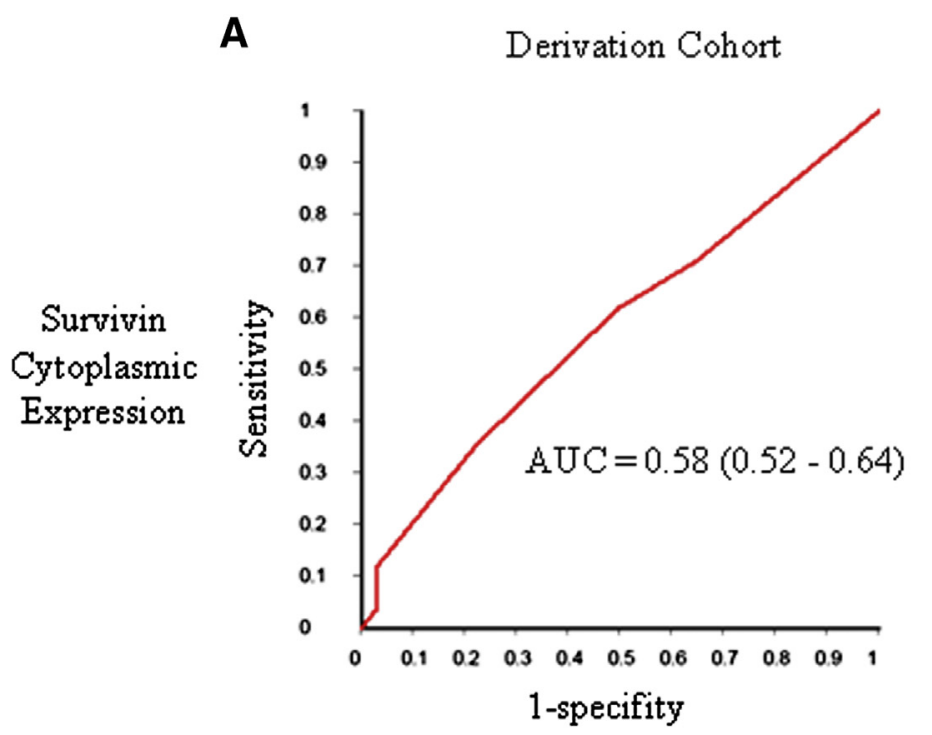

B

Validation Cohort
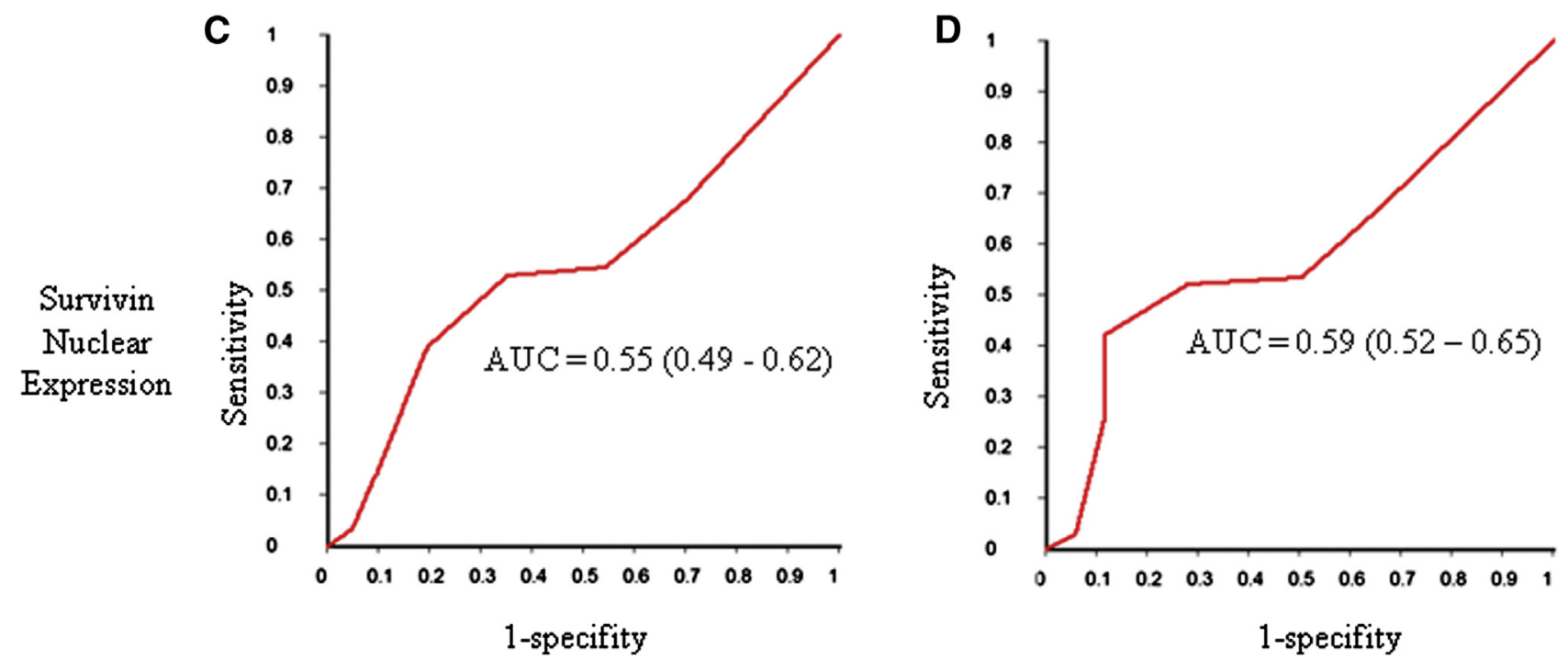

Receiver operating characteristic curves for the prediction of gestational trophoblastic neoplasia with $\mathrm{A}$ and $\mathrm{B}$, cytoplasmic and $\mathrm{C}$ and $\mathrm{D}$, nuclear survivin expression in the 2 cohorts.

$A \cup C$, area under the curve.

Braga et al. Apoptotic index for prediction of postmolar GTN. Am J Obstet Gynecol 2016.

derivation cohort, for an apoptotic index $<4.0 \%$, the risk of GTN was 98 of 200 (0.49; 95\% CI, 0.42-0.56), compared with a risk of 5 of $190(0.03 ; 95 \%$ CI, $0.01-0.06)$ for an apoptotic index $\geq 4.0 \%$, for an odds ratio of 35.55 (95\% CI, 14.02-90.14; $P<.0001)$. This was reproduced in the validation cohort, where the risk of GTN was 82 of $200(0.41 ; 95 \%$ CI, 0.34-0.48) for an apoptotic index $<4.0 \%$, and 5 of $190(0.03 ; 95 \%$ CI, $0.01-0.06)$ for an apoptotic index $\geq 4.0 \%$, for an odds ratio of $25.71 \quad(95 \% \quad$ CI, 10.13-65.29; $P<.0001)$. Although in both cohorts, the positive predictive value for GTN of an apoptotic index $<4.0 \%$ was modest ( $49 \%$ in the derivation cohort and $41 \%$ in the validation cohort), the negative predictive value for GTN of an apoptotic index $\geq 4.0 \%$ was high $(97 \%$ in both cohorts).

\section{Comment}

Our study that involved 780 patients with CHM was the largest cohort in the literature to investigate apoptosis in CHM, and we found a significant correlation between apoptotic index and the progression of CHM to GTN. The 


\section{FIGURE 3}

\section{Performance characteristics of apoptotic index as predictor of GTN following complete mole}

A

Derivation Cohort

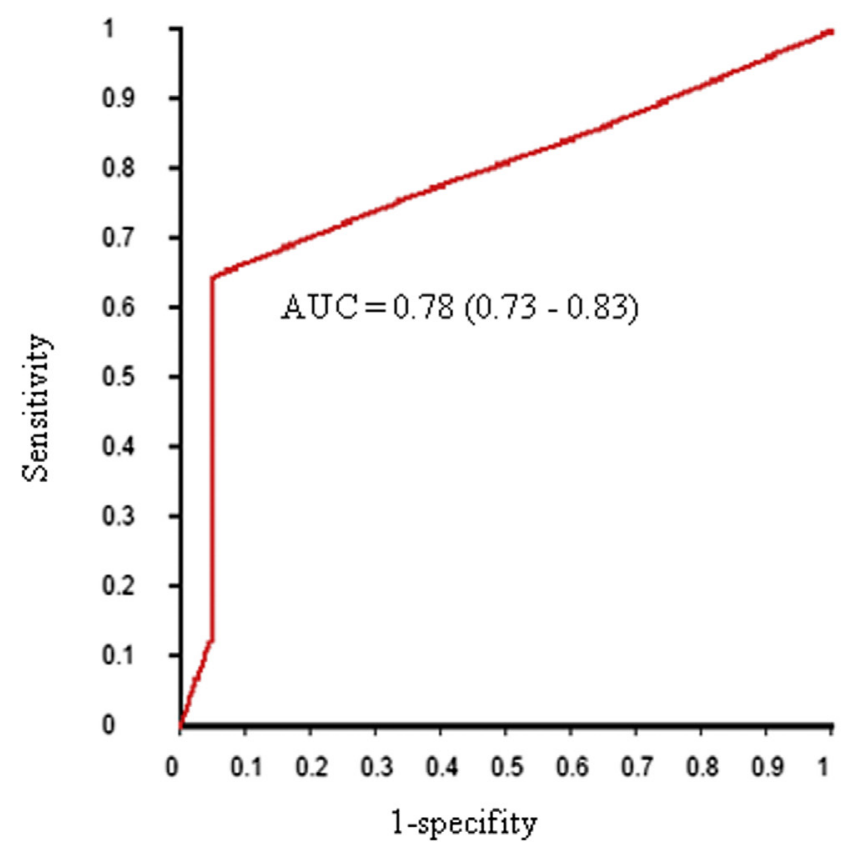

B

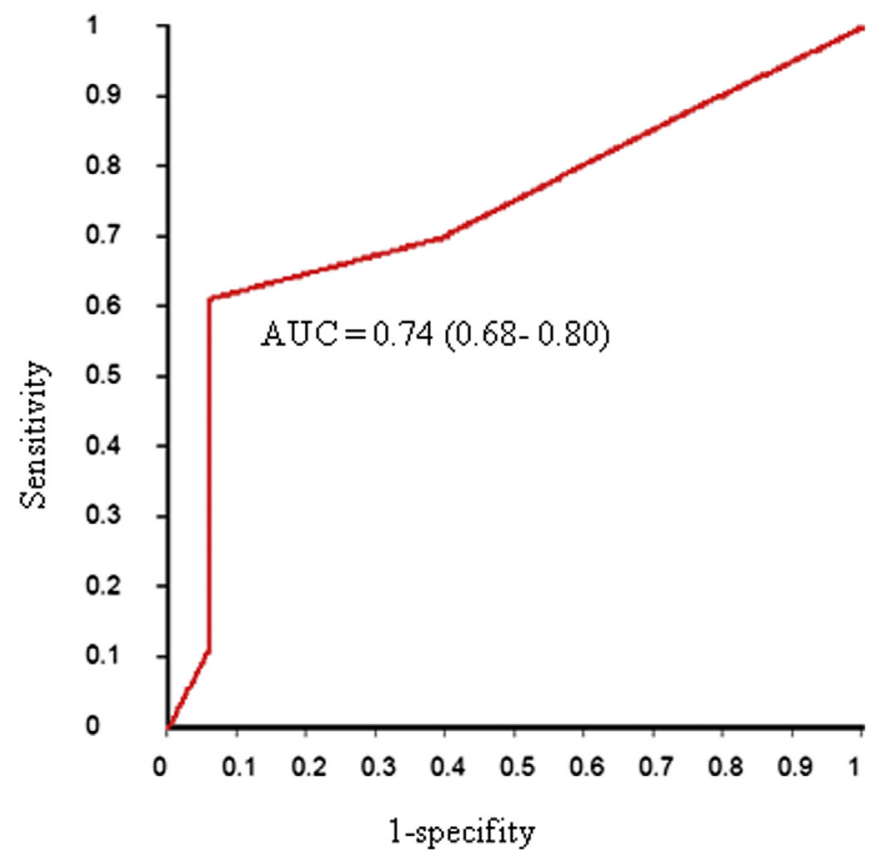

Receiver operating characteristic curves for the prediction of gestational trophoblastic neoplasia with the use of the apoptotic index in the $\mathbf{A}$, derivation and $\mathbf{B}$, validation cohorts.

$A \cup C$, area under the curve.

Braga et al. Apoptotic index for prediction of postmolar GTN. Am J Obstet Gynecol 2016.

present work extends earlier observations regarding the potential role of apoptosis in the prognosis of CHMs. Wong et $\mathrm{al}^{12}$ evaluated 33 normal placentas, 14 miscarriages, 34 complete moles, 14 partial moles, and 8 choriocarcinomas. They found that the apoptotic index was higher in the cases of spontaneous remission of the hydatidiform moles, which indicated that apoptosis could be a prognostic indicator for hydatidiform mole, which is a finding our results corroborate. Chiu et $\mathrm{al}^{13}$ studied the immunohistochemical expression of the caspase cleavage site

\section{TABLE 2}

Apoptotic index and the risk of gestational trophoblastic neoplasia at a cut-off of $4.0 \%$

\begin{tabular}{|c|c|c|c|c|c|c|c|}
\hline Apoptotic index & $\begin{array}{l}\text { Spontaneous } \\
\text { remission, } \mathrm{n}\end{array}$ & $\begin{array}{l}\text { Gestational } \\
\text { trophoblastic } \\
\text { neoplasia, n }\end{array}$ & $\begin{array}{l}\text { Incidence of gestational } \\
\text { trophoblastic neoplasia, } \\
\text { cases per complete mole }\end{array}$ & $\begin{array}{l}95 \% \\
\text { Confidence } \\
\text { interval }\end{array}$ & $\begin{array}{l}\text { Odds } \\
\text { ratio }\end{array}$ & $\begin{array}{l}95 \% \\
\text { Confidence } \\
\text { interval }\end{array}$ & $P$ value \\
\hline Derivation cohort, 1995-2004 & & & & & 35.55 & $14.02-90.14$ & $<.0001^{\mathrm{a}}$ \\
\hline$<4.0 \%$ & 102 & 98 & 0.49 & $0.42-0.56$ & & & \\
\hline$\geq 4.0 \%$ & 185 & 5 & 0.03 & $0.01-0.06$ & & & \\
\hline Validation cohort, 2005-2014 & & & & & 25.71 & $10.13-65.29$ & $<.0001^{b}$ \\
\hline$<4.0 \%$ & 118 & 82 & 0.41 & $0.34-0.48$ & & & \\
\hline$\geq 4.0 \%$ & 185 & 5 & 0.03 & $0.01-0.06$ & & & \\
\hline
\end{tabular}

${ }^{a}$ Fisher's exact test; Sensitivity $=95 \%$; Specificity $=64 \%$; Positive predictive value for GTN of an apoptotic index $<4.0 \%=49 \%$; Negative predictive value for gestational trophoblastic neoplasia of an apoptotic index $\geq 4.0 \%=97 \%$; ${ }^{b}$ Fisher's exact test; Sensitivity $=94 \%$; Specificity $=61 \%$; Positive predictive value for gestational trophoblastic neoplasia of an apoptotic index $<4.0 \%=41 \%$; Negative predictive value for gestational trophoblastic neoplasia of an apoptotic index $\geq 4.0 \%=97 \%$.

Braga et al. Apoptotic index for prediction of postmolar GTN. Am J Obstet Gynecol 2016. 
in cytokeratin 18 using the monoclonal antibody M30 CytoDeath. They analyzed 12 miscarriages, 57 complete moles, 22 partial moles, 8 choriocarcinomas, and 28 normal placentas. They concluded that the lower the presence of M30 in the hydatidiform mole, the higher the incidence of malignant transformation of the trophoblast. Although they did not analyze the presence of caspase-3, Fong et $\mathrm{al}^{15}$ analyzed the expression of caspases 8 and 10 in choriocarcinoma cell lines and firsttrimester placentas. They found that the expression of caspases 8 and 10 was significantly lower in the choriocarcinomas than in normal placenta. Together, these works support our finding that a low apoptotic index indicates a more aggressive trophoblastic disease.

There are no previous studies concerning the potential influence of survivin immunoexpression on the prognosis of patients with CHM. Lehner et $\mathrm{al}^{25}$ studied the expression of survivin in the tissues from 25 normal placentas and 23 hydatidiform moles. Positive survivin expression was observed in 17 of 25 placentas and 22 of 23 hydatidiform moles, with the levels being significantly higher in the hydatidiform moles than in the normal placentas. However, they did not study the association between survivin expression and persistent disease.

Our study did not find a significant correlation between survivin immunoexpression and the progression of CHM to GTN. Survivin is present physiologically in embryonic tissue and is fundamental for fetal development. As gestation progresses, survivin expression levels decrease, and it is not expressed after birth. Survivin reexpression can occur in cancers, however, like lymphomas, gastric and intestinal adenocarcinomas, and pancreatic cancer. Because it is an inhibitor of apoptosis, we would have expected higher survivin expression in cases of CHM that progressed to GTN in parallel with the lower apoptotic index in these cases. However, survivin expression is very context dependent, and higher expression has been associated with both favorable and unfavorable prognoses in different cancer types. ${ }^{26}$ These results suggest that the low apoptotic index that was seen in cases of CHM that progressed to GTN may be due to other mechanisms.

Finally, it is worth noting that, although $95 \%$ of the cases that progressed to GTN had an apoptotic index $<4.0 \%$, there were 10 cases in which the apoptotic index was $>8.0 \%$. All 10 of these cases also had clinical features that were associated with developing GTN, which included the presence of theca lutein cysts, enlarged uterus for gestational age, and initial hCG $\geq 1,000,000$ IU/L. If apoptotic index was to be studied prospectively as a biomarker to predict GTN, this tail effect would have to be considered. It is possible that very large molar burdens may have high apoptosis rates that are related to other factors, such as the cellular proliferation rate or tumor necrosis from hypoxia. This will be an area of future interest.

In conclusion, apoptosis appears to be related closely to the risk of GTN after CHM. We found that a low apoptotic index is associated with a higher risk of GTN. However, the development of postmolar GTN likely is influenced by many factors. Although our comparison of 2 temporal cohorts from Brazil shows that this measure has good internal validity, it will be important to assess the association of the apoptotic index in other patient populations, especially those with lower rates of postmolar GTN than in Brazil, to determine the external validity of this test. Continued study of the molecular biologic condition and gene expression of gestational trophoblastic diseases will likely advance our understanding of these conditions and lead to improved therapy and patient outcomes and potentially broader implications in understanding the pathogenesis of malignancies.

\section{References}

1. Seckl MJ, Sebire NJ, Fisher RA, Golfier F, Massuger L, Sessa C. Gestational trophoblastic disease: ESMO Clinical Practice Guidelines for diagnosis, treatment and follow-up. Ann Oncol 2013;24:vi39-50.

2. Lurain JR. Gestational trophoblastic disease I: epidemiology, pathology, clinical presentation and diagnosis of gestational trophoblastic disease, and management of hydatidiform mole. Am J Obstet Gynecol 2010;203:531-9.

3. Wolfberg AJ, Feltmate C, Goldstein DP, Berkowitz RS, Lieberman E. Low risk of relapse after achieving undetectable HCG levels in women with complete molar pregnancy. Obstet Gynecol 2014;104:551-4.

4. Delmanto LRMG, Maestá I, Braga A, et al. [A curva de regressão da gonadotrofina coriônica humana é útil no diagnóstico precoce da neoplasia trofoblástica gestacional pós-molar?] Rev Bras Ginec Obstet 2007;29:506-10.

5. Genest DR, Laborde O, Berkowitz RS, Goldstein DP, Bernstein MR, Lage J. A clinicopathologic study of 153 cases of complete hydatidiform mole (1980-90) histologic grade lacks prognostic significance. Obstet Gynecol 1991;78:402-9.

6. Van-de-Kaa CA, Schijf CP, de-Wilde PC, et al. Persistent gestational trophoblastic disease: DNA image cytometry and interphase cytogenetics have limited predictive value. Mod Pathol 1996;9:1007-14.

7. Jeffers MD, Richmond JA, Smith R. Trophoblast proliferation rate does not predict progression to persistent gestational trophoblastic disease in complete hydatidiform mole. Int J Gynaecol Pathol 1996;15:34-8.

8. Cheung ANY, Shen DH, Khoo US, et al. Immunohistochemical and mutational analysis of p53 tumour suppressor gene in gestational trophoblastic disease: correlation with mdm2, proliferation index and clinicopathological parameters. Int J Gynaecol Cancer 1999;9: 123-30.

9. Uberti EMH, Fajardo MC, Cunha AGV, et al. Prevention of postmolar gestational trophoblastic neoplasia using prophylactic single bolus dose of actinomycin D in high-risk hydatidiform mole: a simple, effective, secure and low-cost approach without adverse effects on compliance to general follow-up or subsequent treatment. Gynecol Oncol 2009;114:299-305.

10. Kohorn El. Human chorionic gonadotropin follow-up in patients with molar pregnancy: a time for reevaluation. Obstet Gynecol 2003;102: 1417.

11. Batorfi J, Vegh G, Szepesi J, Szigetvari I, Doszpod J, Fulop V. How long should patients be followed after molar pregnancy? Analysis of serum hCG follow-up data. Eur J Obstet Gynecol Reprod Biol 2004;112:95-7.

12. Wong SYY, Ngan HYS, Chan CCW, Cheung ANY. Apoptosis in gestational trophoblastic disease: correlated with clinical outcome and bcl-2 expression but not bax expression. Mod Pathol 1999;12:1025-33.

13. Chiu PM, Ngan YS, Khoo US, Cheung AN. Apoptotic activity in gestational trophoblastic disease correlates with clinical outcome: assessment by the caspase-related M30 CytoDeath antibody. Histopathology 2001;38: 243-9.

14. Shiozaki A, Kakatoa K, Fujimura M, Yubi H, Sakabi M, Saito S. Survivin inhibits apoptosis in cytotrophoblasts. Placenta 2003; 24:65-76. 
15. Fong PY, Xue WC, Ngan HY, et al. Caspase activity is downregulated in choriocarcinoma: a cDNA array differential expression study. J Clin Pathol 2006;59:179-83.

16. Chan $H Y$, Siu MKY, Zhang HJ, et al. Activated Stat3 expression in gestational trophoblastic disease: correlation with clinicopathological parameters and apoptotic indices. Histopathology 2008;53:139-46.

17. Fadeel B, Orrenius S. Apoptosis: a basic biological phenomenon with wide-ranging implications in human disease. J Intern Med 2005;258:479-517.

18. Monzo M, Rosell R, Felip E, et al. A novel anti apoptosis gene: Re expression of survivin messenger RNA as a prognosis marker in no small cell lung cancer. J Clin Oncol 1999;17: 2100-4.

19. Verdecia AM, Huang HK, Dutil E, Kaiser DA, Hunter T, Noel JP. Structure of the human anti apoptotic protein survivin reveals a dimeric arrangement. Nature 2000; 7:602-8.

20. FIGO Oncology Committee. FIGO staging for gestational trophoblastic neoplasia 2000. Int $J$ Gynecol Obstet 2002;77:285-7.

21. Michelin OC, Maestá I, Braga A, Gaspari LRS, Delmanto LRMG, Consonni M. Treatment of gestational trophoblastic neoplasia resistant to methotrexate. Femina 2007;35: 35-40.

22. Szulman AE, Surti U. The syndromes of partial and complete molar gestation. Clin Obstet Gynecol 1984;27:172-80.

23. Sgarbosa F, Barbisan LF, Brasil MA, et al. Changes in apoptosis and $\mathrm{Bcl}-2$ expression in human hyperglycemic, term placental trophoblast. Diabetes Res Clin Pract 2006;73: 143-9.

24. Dean AG, Sullivan KM, Soe MM. OpenEpi: Open Source Epidemiologic Statistics for Public Health, Version. Available at: www.OpenEpi.com (updated 2015/05/04). Accessed February 8, 2016.

25. Lehner R, Bobak J, Kim NK, Shroyer AL, Shroyer KR. Localization of telomerase hTERT protein and survivin in placenta: relation to placental development and hydatidiform mole. Obstet Gynecol 2001;97:965-70.

26. Knauer SK, Mann W, Stauber RH. Survivin's dual role: an export's view. Cell Cycle 2007;6: 518-21.

\section{Author and article information}

From Rio de Janeiro Trophoblastic Disease Center, Maternity School of Rio de Janeiro Federal University and Antonio Pedro University Hospital of Fluminense Federal University (Dr Braga); Postgraduate Program of Gynecology, Obstetrics and Mastology, Botucatu Medical School (Drs Braga, Maestá, and Rocha Saores); Department of Pathology, Botucatu Medical School (Dr Custodio Domingues); Department of Morphology, Biosciences Institute, (Dr Barbisan), São Paulo State University, Brazil; and New England Trophoblastic Disease Center, Donald P. Goldstein MD Trophoblastic Tumor Registry, Division of Gynecologic Oncology, Department of Obstetrics and Gynecology and Reproductive Biology, Brigham and Women's Hospital, Dana-Farber Cancer Institute, Boston, MA (Drs Elias and Berkowitz).

Received Feb. 16, 2016; revised April 2, 2016; accepted April 8, 2016.

Supported by the Carlos Chagas Filho Foundation for Research Support in the State of Rio de Janeiro/Brazil (FAPERJ), which is an agency under the Brazilian Ministry of Science and Technology, and the Donald P. Goldstein MD Trophoblastic Tumor Registry Endowment and the Dyett Family Trophoblastic Disease Research and Registry Endowment.

The funding agencies had no direct role in the generation of the data or manuscript.

The authors report no conflict of interest.

Corresponding author: Kevin M. Elias, MD. kelias1@ partners.org 


\section{SUPPLEMENTAL FIGURE 1 \\ Examples of \\ immunohistochemical staining for survivin}

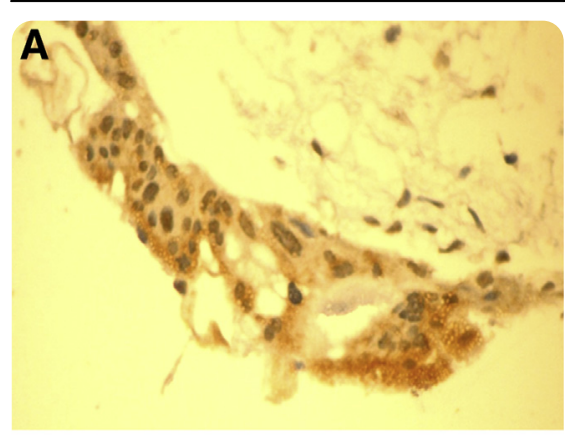

B

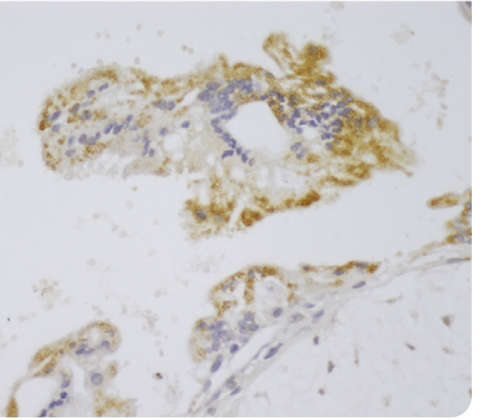

A, Nuclear survivin staining; B, Cytoplasmic survivin staining.

Braga et al. Apoptotic index for prediction of postmolar GTN. Am J Obstet Gynecol 2016.

\section{SUPPLEMENTAL FIGURE 2 Examples of cleaved caspase-3 staining}
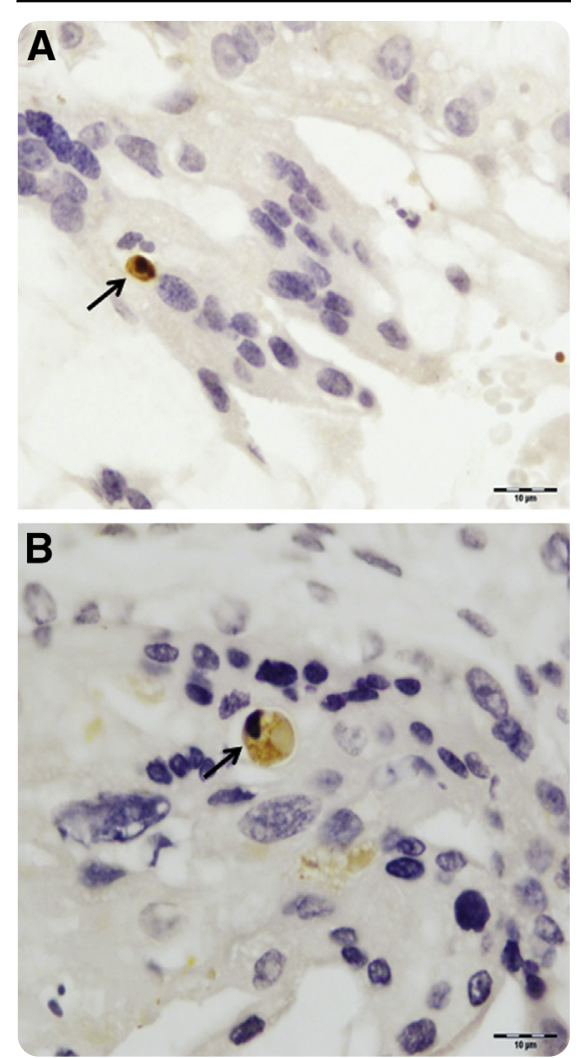

A, Representative image of a cleaved caspase-3 positive cell (arrow) identified by brown cytoplasmic staining. B, Apoptotic cell (arrow) shows a clear cell retraction and condensed chromatin. Braga et al. Apoptotic index for prediction of postmolar GTN. Am J Obstet Gynecol 2016. 


\section{SUPPLEMENTAL TABLE 1}

\section{Relationship between apoptosis biomarkers and clinical outcome for gestational trophoblastic neoplasia}

\begin{tabular}{|c|c|c|c|c|}
\hline Factor \& outcome & Estimate of $\beta$ coefficient & $P$ value $^{\mathrm{a}}$ & Odds ratio & 95\% Confidence interval \\
\hline \multicolumn{5}{|l|}{ Apoptotic index } \\
\hline Start of chemotherapy $<8$ wk & -0.41 & .38 & 0.66 & $0.27-1.65$ \\
\hline Presence of metastasis & -0.07 & .92 & 0.94 & $0.24-3.59$ \\
\hline Chemoresistance & -0.29 & .52 & 0.75 & $0.30-1.84$ \\
\hline Multiagent chemotherapy & -0.30 & 62 & 0.74 & $0.19-2.95$ \\
\hline \multicolumn{5}{|l|}{ Cytoplasmic survivin expression } \\
\hline Start of chemotherapy $<8$ wk & 1.46 & .24 & 4.29 & $0.39-47.62$ \\
\hline Presence of metastasis & -19.59 & 1.0 & 0.00 & $0.00-\infty$ \\
\hline Chemoresistance & -0.51 & 64 & 0.60 & $0.07-5.06$ \\
\hline Multiagent chemotherapy & -0.88 & .56 & 0.42 & $0.02-8.05$ \\
\hline \multicolumn{5}{|l|}{ Nuclear survivin expression } \\
\hline Start of chemotherapy $<8$ wk & 0.41 & 68 & 1.50 & $0.22-10.22$ \\
\hline Presence of metastasis & -18.80 & 1.0 & 0.00 & $0.00-\infty$ \\
\hline Chemoresistance & 0.18 & .87 & 1.20 & $0.15-9.77$ \\
\hline Multiagent chemotherapy & 0.61 & 69 & 1.83 & $0.10-34.85$ \\
\hline
\end{tabular}

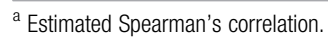

Braga et al. Apoptotic index for prediction of postmolar GTN. Am J Obstet Gynecol 2016. 


\section{SUPPLEMENTAL TABLE 2}

\section{Relationship between survivin expression and the risk of gestational trophoblastic neoplasia}

\begin{tabular}{|c|c|c|c|c|c|c|c|c|c|c|}
\hline \multirow[b]{2}{*}{ IHC Score } & \multicolumn{5}{|l|}{ Cytoplasmic } & \multicolumn{5}{|l|}{ Nuclear } \\
\hline & $\begin{array}{l}\text { Spontaneous } \\
\text { remission, } \mathrm{n}\end{array}$ & $\begin{array}{l}\text { Gestational } \\
\text { trophoblastic } \\
\text { neoplasia, } \mathrm{n}\end{array}$ & $\begin{array}{l}\text { Incidence of gestational } \\
\text { trophoblastic neoplasia, } \\
\text { cases per complete mole }\end{array}$ & $\begin{array}{l}95 \% \\
\text { Confidence } \\
\text { interval }\end{array}$ & $P$ trend & $\begin{array}{l}\text { Spontaneous } \\
\text { remission, } \mathrm{n}\end{array}$ & $\begin{array}{l}\text { Gestational } \\
\text { trophoblastic } \\
\text { neoplasia, } n\end{array}$ & $\begin{array}{l}\text { Incidence of gestational } \\
\text { trophoblastic neoplasia, } \\
\text { cases per complete mole }\end{array}$ & $\begin{array}{l}95 \% \\
\text { Confidence } \\
\text { interval }\end{array}$ & $P$ trend \\
\hline \multicolumn{11}{|l|}{ Derivation cohort } \\
\hline 0 & 85 & 37 & 0.30 & $0.23-0.39$ & $.02^{\mathrm{a}}$ & 90 & 30 & 0.25 & $0.18-0.33$ & $.08^{\mathrm{a}}$ \\
\hline 1 & 0 & 0 & 0 & $\infty$ & & 40 & 17 & 0.30 & $0.19-0.43$ & \\
\hline 2 & 25 & 15 & 0.38 & $0.24-0.53$ & & 5 & 20 & 0.80 & $0.60-0.92$ & \\
\hline 3 & 75 & 28 & 0.27 & $0.19-0.37$ & & 40 & 16 & 0.29 & $0.18-0.42$ & \\
\hline 4 & 68 & 20 & 0.23 & $0.15-0.33$ & & 70 & 10 & 0.13 & $0.07-0.22$ & \\
\hline 5 & 24 & 0 & 0 & $0-0.16$ & & 32 & 5 & 0.14 & $0.05-0.28$ & \\
\hline 6 & 10 & 3 & 0.23 & $0.07-0.51$ & & 10 & 5 & 0.33 & $0.15-0.59$ & \\
\hline Validation cohort & & & & & $.74^{\mathrm{a}}$ & & & & & $.005^{\mathrm{a}}$ \\
\hline 0 & 105 & 23 & 0.18 & $0.12-0.26$ & & 100 & 30 & 0.23 & $0.17-0.31$ & \\
\hline 1 & 0 & 0 & 0 & $\infty$ & & 40 & 13 & 0.25 & $0.15-0.38$ & \\
\hline 2 & 25 & 15 & 0.38 & $0.24-0.53$ & & 5 & 20 & 0.80 & $0.60-0.92$ & \\
\hline 3 & 65 & 22 & 0.25 & $0.17-0.35$ & & 30 & 14 & 0.32 & $0.20-0.47$ & \\
\hline 4 & 62 & 20 & 0.24 & $0.16-0.35$ & & 50 & 0 & 0 & $0-0.08$ & \\
\hline 5 & 36 & 0 & 0 & $0-0.11$ & & 68 & 5 & 0.07 & $0.03-0.15$ & \\
\hline 6 & 10 & 7 & 0.41 & $0.22-0.64$ & & 10 & 5 & 0.33 & $0.15-0.59$ & \\
\hline
\end{tabular}




\section{SUPPLEMENTAL TABLE 3}

\section{Relationship between apoptotic index and the risk of gestational trophoblastic neoplasia}

\begin{tabular}{|c|c|c|c|c|c|}
\hline Apoptotic index & $\begin{array}{l}\text { Spontaneous } \\
\text { remission }(n)\end{array}$ & $\begin{array}{l}\text { Gestational trophoblastic } \\
\text { neoplasia }(\mathrm{n})\end{array}$ & $\begin{array}{l}\text { Incidence of gestational } \\
\text { trophoblastic neoplasia, } \\
\text { cases per complete mole }\end{array}$ & $\begin{array}{l}95 \% \text { Confidence } \\
\text { interval }\end{array}$ & $P$ trend \\
\hline Derivation cohort, \% & & & & & $<.0001^{\mathrm{a}}$ \\
\hline$<2.0$ & 40 & 36 & 0.47 & $0.36-0.58$ & \\
\hline $2.0-2.9$ & 30 & 32 & 0.51 & $0.39-0.64$ & \\
\hline $3.0-3.9$ & 32 & 30 & 0.48 & $0.36-0.60$ & \\
\hline $4.0-4.9$ & 25 & 0 & 0 & $0-0.16$ & \\
\hline $5.0-5.9$ & 35 & 0 & 0 & $0-0.12$ & \\
\hline $6.0-6.9$ & 45 & 0 & 0 & $0-0.09$ & \\
\hline $7.0-7.9$ & 43 & 0 & 0 & $0-0.10$ & \\
\hline $8.0-9.1$ & 37 & 5 & 0.11 & $0.05-0.25$ & \\
\hline Validation cohort, \% & & & & & $<.0001^{a}$ \\
\hline$<2.0$ & 40 & 24 & 0.41 & $0.27-0.50$ & \\
\hline $2.0-2.9$ & 50 & 28 & 0.37 & $0.26-0.47$ & \\
\hline $3.0-3.9$ & 28 & 30 & 0.53 & $0.39-0.64$ & \\
\hline $4.0-4.9$ & 35 & 0 & 0 & $0-0.12$ & \\
\hline $5.0-5.9$ & 25 & 0 & 0 & $0-0.16$ & \\
\hline $6.0-6.9$ & 45 & 0 & 0 & $0-0.09$ & \\
\hline $7.0-7.9$ & 47 & 0 & 0 & $0-0.09$ & \\
\hline $8.0-9.1$ & 33 & 5 & 0.13 & $0.05-0.28$ & \\
\hline
\end{tabular}

${ }^{a}$ Mantel-Haenszel chi-square.

Braga et al. Apoptotic index for prediction of postmolar GTN. Am J Obstet Gynecol 2016. 